\title{
Estrogen receptor $\beta$ inhibits estradiol-induced proliferation and migration of MCF-7 cells through regulation of mitofusin 2
}

\author{
LI MA $^{1,2}$, YUEPING LIU ${ }^{3}$, CUIZHI GENG ${ }^{2}$, XIAOWEI QI ${ }^{1}$ and JUN JIANG ${ }^{1}$ \\ ${ }^{1}$ Breast Disease Center, Southwest Hospital, Third Military Medical University, Chongqing; \\ Departments of ${ }^{2}$ Breast Disease Center and ${ }^{3}$ Pathology, The Fourth Hospital of \\ Hebei Medical University, Shijiazhuang, P.R. China
}

Received February 5, 2013; Accepted March 15, 2013

DOI: 10.3892/ijo.2013.1903

\begin{abstract}
In the present study, we investigated whether estrogen receptor (ER) $\beta$ affected the proliferation and migration of the human breast cancer cell line MCF-7 through regulation of mitofusin $2(\mathrm{mfn} 2)$. A previous study reported that $\mathrm{mfn} 2$ may be regulated by ER through a non-classical pathway; in this pathway, the ER modulates the activities of other transcription factors by stabilizing their binding to DNA and/or recruiting coactivators to the complex. However, the previous study, unlike the study presented here, did not directly explore the interactions between ER and mfn2. Here, RT-PCR and western blot analysis were used to test the expression of $\mathrm{mfn} 2$ in MCF-7 cells after exposure to different doses of estradiol (E2). The ability of cells to proliferate and migrate was determined by MTT assay and a monolayer-wounding protocol, respectively. Finally, changes in MCF-7 cell biology after transfection with ER $\beta$ or $\mathrm{mfn} 2$ expression vectors were investigated, and the role of ER $\beta$ in $\mathrm{mfn} 2$ expression was also explored. Our results showed that E2 attenuated $\mathrm{mfn} 2$ expression in a dose-dependent manner, concomitant with the activation of proliferation and migration of MCF-7 cells. The mfn 2 expression vector effectively suppressed E2-induced upregulation of PCNA and migration in MCF-7 cells. ER $\beta$ inhibited the E2-induced mfn2 downregulation that accompanied the inhibition of proliferation and migration in MCF-7 cells. Briefly, ER $\beta$ may inhibit E2-induced proliferation and migration of MCF-7 cells through regulation of $\mathrm{mfn} 2$.
\end{abstract}

\section{Introduction}

Both clinical and epidemiological evidence show that estrogens participate in the initiation and development of human breast cancer $(1,2)$. Understanding the role of both types of estrogen

Correspondence to: Professor Jun Jiang, Breast Disease Center, Southwest Hospital, Third Military Medical University, no. 30 Gaotanyan Street, Chongqing City, P.R. China

E-mail: jiangjunxn@126.com

Key words: breast cancer, estrogen receptor $\beta$, mitofusin 2, proliferation, migration receptor (ER) (ER $\alpha$ and $E R \beta)$, in the pathogenesis of breast cancer is important, because effects of estrogen are mediated through both of these ERs (3-6). Although the function of ER $\alpha$ has been established and its remains the most important marker of response to hormonal therapy in breast cancer, the role of ER $\beta$ remains elusive with many conflicting studies (7). The two ERs act in distinct ways in several estrogen target cells and tissues $(8,9)$. There are two major conclusions to be drawn from current research situation of ERs. First, ER $\alpha$ and ER $\beta$ have different biological functions, which are indicated by their distinct expression patterns and the different phenotypes reported for the two ERs in knockout animals, respectively. Second, ER $\alpha$ and ER $\beta$ have overlapping yet unique roles in estrogen signaling, as judged from a number of gene expression profiling studies.

Mitofusin 2 ( $\mathrm{mfn} 2)$, also named as hyperplasia suppressor gene for its antiproliferative effects, localizes to the mitochondrial outer membrane and plays an essential role in mitochondrial fusion, thus regulating mitochondrial morphology and function. Chen et al (10) recently demonstrated that $\mathrm{mfn} 2$ profoundly suppresses cell growth and proliferation in multiple tumor cell lines and rat vascular smooth muscle cells in vivo and in culture systems via inhibition of the Ras-ERK MAPK signaling pathway. Also, there is some evidence suggesting a protective effect of $\mathrm{mfn} 2$ in mammalian cells (11-13).

There is a growing body of literature suggesting that estrogen may modulate expression of some genes through a non-classical pathway in which the ER interacts with other transcription factors, a process referred to as transcription factor cross-talk. In this pathway, the ER modulates the activities of other transcription factors, such as activator protein (AP)-1, by stabilizing their binding to DNA and/or recruiting coactivators to the complex. DeNardo et al (14) identified sets of estrogen-induced genes, including $\mathrm{mfn} 2$, whose promoters contain potential AP-1 sites but no estrogen-responsive element (ERE) sequences, essential for a classical model of estrogen action; these genes thus depend on AP-1 for their expression. Further characterization of the promoters suggested that the ER regulated these genes through the non-classical pathways mentioned above. However, the previous study, unlike the study presented here, did not directly explore the interaction between ERs and $\mathrm{mfn} 2$.

In the present study, we showed that ER $\beta$ inhibits human breast cancer cell proliferation and migration by inducing 
expression of $\mathrm{mfn} 2$. We report for the first time that ER $\beta$ acts upstream of $\mathrm{mfn} 2$. Moreover, this observation indicated that $\mathrm{mfn} 2$ affects the proliferation and migration of human breast cancer cells.

\section{Materials and methods}

Cell lines and groups. MCF-7, a human breast cancer cell line, was kindly provided by Professor Mei-xiang Sang, Division of Scientific Research, the Fourth Hospital of Hebei Medical University, Shijiazhuang, China. Cells were cultured in growth medium consisting of Dulbecco's modified Eagle's medium (DMEM) (Gibco-BRL, USA) containing $4.5 \mathrm{~g} / 1$ glucose, $2 \mathrm{mM}$ L-glutamine, $5,000 \mathrm{IU} / 1$ penicillin, $5 \mathrm{mg} / 1$ streptomycin, $125 \mathrm{U} / 1$ Fungizone, $2.2 \mathrm{~g} / 1$ sodium bicarbonate and $10 \%$ fetal bovine serum (FBS) pretreated by $5 \%$ charcoal-dextran, in a $5 \% \mathrm{CO}_{2}$ incubator. For experiments carried out in serum-free conditions, cells were made quiescent by culturing in serum-free medium for $24 \mathrm{~h}$. DMEM with antibiotics and glutamine, was supplemented with $0.5 \mathrm{~g} / 1 \mathrm{BSA}$ (1). Cells were randomly divided into six groups and cultured for $48 \mathrm{~h}$ with E2 (17 $\beta$-estradiol, at doses of $0 \mathrm{~mol} / 1$ group, $10^{-9} \mathrm{~mol} / 1$ group, $10^{-8} \mathrm{~mol} / 1$ group, $10^{-7} \mathrm{~mol} / 1$ group, $10^{-6} \mathrm{~mol} / 1$ group and $10^{-5} \mathrm{~mol} / \mathrm{l}$ ) to determine the dose-dependent effects of E2 on $\mathrm{mfn} 2$ and cell behavior. Cells of each group were cultured for $48 \mathrm{~h}$ in DMEM medium containing 10\% FBS plus defferent dose of E2 without phenolsulfonphthalein (2). To specially enhance $\mathrm{mfn} 2$ expression and explore its effect on proliferation and migration of MCF-7 cells, cells were randomly divided into four groups in gene transfection experiments as follows: normal group (blank control), untransfected E2 group (E2), control vector pEGFP-transfected E2 group (E2 plus control vector) and pEGFP-mfn2-transfected $\mathrm{E} 2$ group (E2 plus mfn2 vector). Cells of the three groups treated with E2 were cultured in DMEM with $10 \% \mathrm{FBS}$ plus $10^{-6} \mathrm{~mol} / \mathrm{l}$ $\mathrm{E} 2$ for $48 \mathrm{~h}$ (3). To explore the effect of ER $\beta$ on $\mathrm{mfn} 2$ expression, cells were randomly divided into four groups as follows: normal group (blank control), untransfected E2 group (E2), control vector pEGFP-N1 E2 group (E2 plus control vector) and pEGFP-N1-ESR2 E2 group (E2 plus ER $\beta$ vector). Cells of every group were grown as described in group 2 . Each experiment was repeated six times.

Expression vectors and transient transfection. The pEGFP-mfn2 and pEGFP-N1-ESR2 vectors and their negative control vectors were purchased from Yingrun Biotechnology Co. Ltd., (Changsha, China). pEGFP-mfn2 and pEGFP-N1-ESR2 plasmids carry full-length $\mathrm{mfn} 2$ and ER $\beta$ genes, respectively. Transient transfection of MCF-7 cells was carried out using Lipofectamine 2000 (Invitrogen Co., Carlsbad, CA, USA) according to the manufacturer's instructions. Briefly, MCF-7 cells were cultured in 6-well plates and the medium was changed the following day until $80 \%$ confluence was achieved. The cells were transfected with $4.0 \mu \mathrm{g}$ vector DNA by $10 \mu \mathrm{l}$ Lipofectamine 2000 in $2 \mathrm{ml}$ serum-free DMEM medium. At $6 \mathrm{~h}$ after transfection, the medium was replaced by normal DMEM supplemented with $10 \% \mathrm{FBS}$, and cells were cultured for $24 \mathrm{~h}$. Cells were then cultured for $48 \mathrm{~h}$ in medium containing 10\% FBS and E2 to detect proliferation and migration of MCF-7 cells (group 2) and $\mathrm{mfn} 2$ expression (group 3). The efficiency of transfection was approximately $70 \%$ for all experimental groups.
Table I. Primers and corresponding products for $\mathrm{mfn} 2$ and GAPDH.

Products

Gene

(bp)

$\mathrm{mfn} 2$

Sense 5'-ATGCATCCCCACTTAAGCAC-3'

Antisense 5'-CCAGAGGGCAGAACTTTGTC-3'

GAPDH

Sense 5'-AACGGATTTGGTCGTATTG-3'

214

Antisense 5'-GCTCCTGGAAGATGGTGAT-3'

Western blot analysis. Protein extracted from MCF-7 cells was separated on a $10 \%$ SDS-PAGE gel and then transferred onto PVDF membrane (Millipore Corporation, Bedford, MA, USA). The membrane was blocked for $1 \mathrm{~h}$ at $37^{\circ} \mathrm{C}$ with $5 \% \mathrm{BSA}$ in Tris-buffered saline containing $0.05 \%$ Tween-20 (TBST). Next, the membrane was incubated at $4^{\circ} \mathrm{C}$ overnight with primary antibodies for mfn2 (1:200, Santa Cruz Biotechnology, Santa Cruz, CA, USA), ER $\beta$ (1:100, Santa Cruz Biotechnology), and $\beta$-actin (1:1,000, Santa Cruz Biotechnology). Subsequently, the membrane was rinsed three times with TBST containing secondary antibody $(1: 5,000)$, treated with ECL solution (Pierce, Rockford, IL, USA), and bands detected by exposing the blots to X-ray film. For quantitative analysis (i.e., normalized for $\beta$-actin), bands were evaluated with IPP 5.0 software. Integrated optical density (IOD) of each band was measured, and relative IOD calculated as the ratio of the target band IOD compared to the IOD of the $\beta$-actin band.

Semi-quantitative RT-PCR. Total RNA was extracted with TRIzol (Invitrogen Co.) according to the manufacturer's instructions. Total RNA $(2 \mu \mathrm{g})$ was reverse transcribed using random primers and M-MLV at $42^{\circ} \mathrm{C}$ for $1 \mathrm{~h}$ and then heated to $94^{\circ} \mathrm{C}$ for $5 \mathrm{~min}$ in a total reaction volume of $20 \mu \mathrm{l}$. The PCR amplification began with a 5 -min denaturation at $95^{\circ} \mathrm{C}$, followed by 40 cycles of denaturation at $95^{\circ} \mathrm{C}$ for $45 \mathrm{sec}$, annealing at $55^{\circ} \mathrm{C}$ for $45 \mathrm{sec}$ and extension at $72^{\circ} \mathrm{C}$ for $60 \mathrm{sec}$. The final extension was set for $10 \mathrm{~min}$ at $72^{\circ} \mathrm{C}$. The products were electrophoresed on a $1.5 \%$ agarose gel, and the levels of mfn2 mRNA were normalized with levels of GAPDH mRNA. All PCR primers are shown in Table I.

Immunofluorescence. MCF-7 cells were planted on cover slides in 6-well plates. After fixing with $10 \%$ formalin at room temperature for $15 \mathrm{~min}$, pretreating with $0.3 \%$ Triton X-100 for $20 \mathrm{~min}$ at $37^{\circ} \mathrm{C}$ and blocking with goat serum for $30 \mathrm{~min}$ at $37^{\circ} \mathrm{C}$, cells were incubated with anti-mfn2 (1:200) overnight at $4^{\circ} \mathrm{C}$. After washing with PBS for three times, the slides was all incubated with FITC-conjugated secondary antibody (1:200, Santa Cruz Biotechnology) for $2 \mathrm{~h}$ at $37^{\circ} \mathrm{C}$. Then slides were viewed after being rinsed with PBS three times.

Cell proliferation. Cell proliferation was measured using methyl thiazolyl tetrazolium (MTT) shade selection experiments. Cells $\left(5 \times 10^{3}\right.$ per well) were plated in triplicate in 96-well 
A
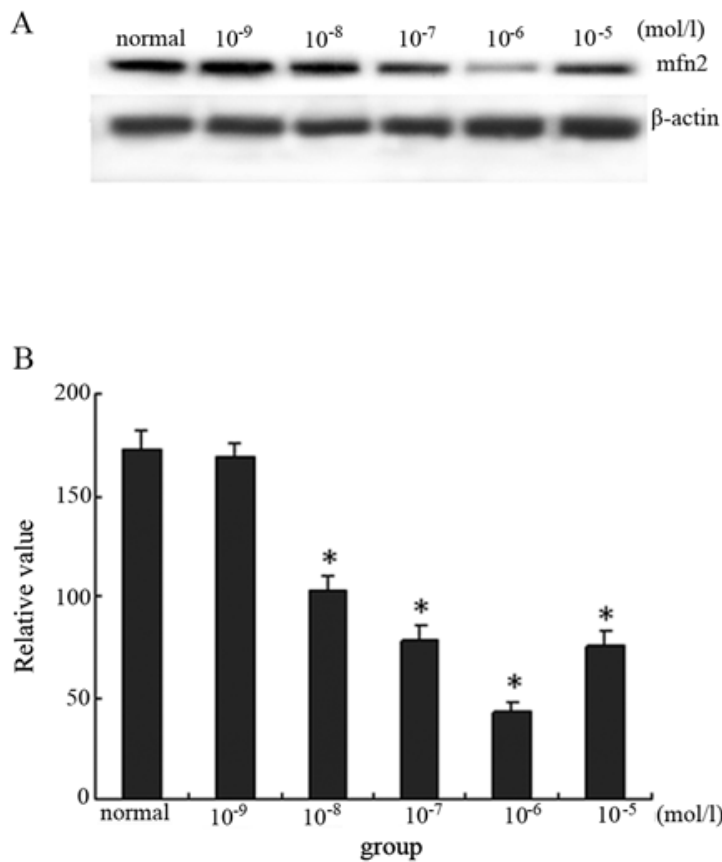

$\mathrm{C}$

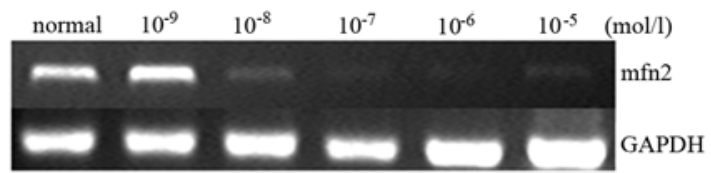

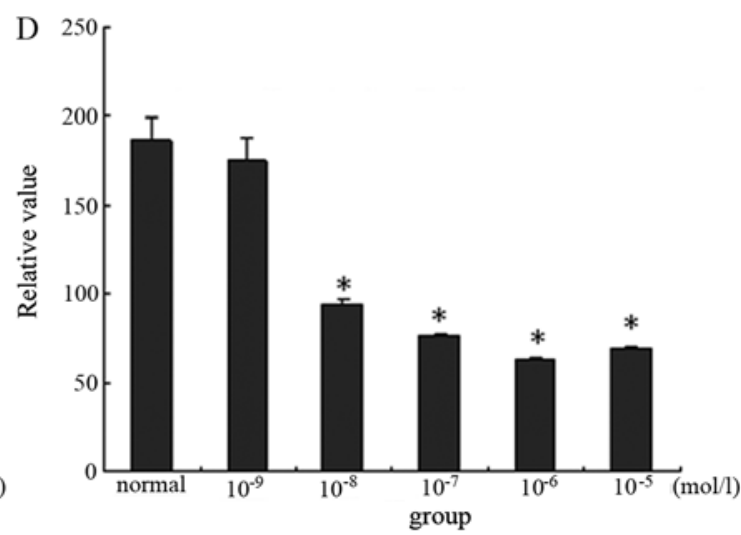

Figure 1.E2 downregulates expression of $\mathrm{mfn} 2$ in a dose-dependent manner in MCF-7 cells. (A) Western blot analysis of the dose-dependent effects of E2 on mfn2 expression. (B) Protein levels of $\mathrm{mfn} 2$ were quantified by densitometry (mean $\pm \mathrm{SD}, \mathrm{n}=6$ ). " $\mathrm{P}<0.05$ vs. normal group. (C) mRNA levels of mfn2 were determined by RT-PCR. (D) mRNA levels of $\mathrm{mfn} 2$ were quantified by densitometry (mean $\pm \mathrm{SD}, \mathrm{n}=6$ ). ${ }^{*} \mathrm{P}<0.01$ versus normal group.

plates and cultured for $24 \mathrm{~h}$. Then, 3-2,5-dihydro-1-methyl5h-tetrazole-5-thion sodium salt was added for $4 \mathrm{~h}$ before absorbance was determined at $490 \mathrm{~nm}$ (SpectraMax, Molecular Devices, Sunnyvale, CA, USA).

Measurement of cell migration. Cell migration was measured using a wound-healing protocol developed and described in an earlier publication (15).

Statistical analysis. The figure analysis was carried out by the software of IPP. The quantitative data are presented as mean \pm standard deviation (SD). Statistical analyses were performed using one-way analysis of variance (ANOVA) with Student-Newman-Keuls test. Statistical differences were considered significant at a $\mathrm{P}$-value of $<0.05$.

\section{Results}

E2 downregulates expression of $m f n 2$ in a dose-dependent manner in MCF-7 cells. As described above, the ER might regulate $\mathrm{mfn} 2$ expression via a non-classical pathway. To observe the effect of ER $\alpha$ on $\mathrm{mfn} 2, \mathrm{MCF}-7$ cells, which primarily express $\mathrm{ER} \alpha$, were cultured in medium containing E2. The effect of E2 on mfn 2 expression through ER $\alpha$ was measured using immunoblotting for protein levels and semi-quantitative RT-PCR for mRNA levels in MCF-7 cells. E2 inhibited the expression of $\mathrm{mfn} 2$ in a dose-dependent manner. Mfn2 was expressed at a higher level in cells cultured with $10 \% \mathrm{FBS}$. When cells were pretreated with $10^{-9} \mathrm{~mol} / 1,10^{-8} \mathrm{~mol} / 1,10^{-7} \mathrm{~mol} / 1,10^{-6} \mathrm{~mol} / 1$ and $10^{-5} \mathrm{~mol} / 1$ group E2 for $48 \mathrm{~h}$, protein expression of $\mathrm{mfn} 2$ decreased by $2.85,40.00,55.43,74.29$ and $57.14 \%$, respectively. Thus, the lowest expression of $\mathrm{mfn} 2$ was seen in the $10^{-6} \mathrm{~mol} / \mathrm{l}$ group. Similar changes were seen when cells were analyzed by
RT-PCR. These findings demonstrated that E2 decreased mfn2 expression in a dose-dependent manner at both the molecular and protein levels (Fig. 1).

E2 enhances proliferation and migration of MCF-7 cells. MCF-7 cells are the best-characterized ER-positive cell line in terms of known genes regulated by estrogens that promote proliferation. In order to confirm that E2 promotes proliferation, E2-treated MCF-7 cells were examined using an MTT assay. Absorbance of the MTT substrate at $490 \mathrm{~nm}$ for each dosage group is showed in Table II. Significant differences were seen among experimental groups and the control group; the maximum effect of E2 on proliferation was seen in the $10^{-6} \mathrm{~mol} / \mathrm{l}$ group, where $\mathrm{mfn} 2$ was expressed at its lowest level. These results demonstrated that E2 treatment resulted in increased proliferation of MCF-7 cells, and that decreased $\mathrm{mfn} 2$ might play a positive role in this proliferation.

To determine if E2 influenced cell motility, we examined the ability of treated cells to migrate in a wound-healing assay. In response to wounding the monolayer, the $10^{-6} \mathrm{~mol} / \mathrm{l}$ group cells were able to almost completely heal the wound. In contrast, the cells of other groups were unable to do so and exhibited an obvious reduction in their rate of migration compared to the $10^{-6} \mathrm{~mol} / \mathrm{l}$ group. As compared with the $10^{-6} \mathrm{~mol} / \mathrm{l}$ group cells, the reduction in the migration rate of cells treated with E2 at $10^{-9} \mathrm{~mol} / 1,10^{-8} \mathrm{~mol} / 1,10^{-7} \mathrm{~mol} / 1,10^{-5} \mathrm{~mol} / 1$ and $0 \mathrm{~mol} / 1$ were $64.3,50.0,31.4,24.5$ and $85.7 \%$, respectively. These results demonstrated that E2 also enhanced cell motility in a dose-dependent manner (Fig. 2).

The mfn2 expression vector effectively suppressed E2-induced upregulation of PCNA and migration in MCF-7 cells. A previous study demonstrated that $\mathrm{mfn} 2$ profoundly suppresses 
Table II. E2 enhances proliferation of MCF-7 cells as quantified by MTT assay.

\begin{tabular}{llc}
\hline Group $(\mathrm{mol} / \mathrm{l})$ & $\mathrm{n}$ & OD value $(\mathrm{x} \pm \mathrm{s})$ \\
\hline Control & 6 & $0.45 \pm 0.18$ \\
$10^{-9}$ & 6 & $0.54 \pm 0.10$ \\
$10^{-8}$ & 6 & $0.62 \pm 0.16^{\mathrm{a}}$ \\
$10^{-7}$ & 6 & $0.71 \pm 0.15^{\mathrm{a}}$ \\
$10^{-6}$ & 6 & $0.97 \pm 0.06^{\mathrm{a}}$ \\
$10^{-5}$ & 6 & $0.89 \pm 0.11^{\mathrm{a}}$ \\
\hline
\end{tabular}

${ }^{*} \mathrm{P}<0.01$ vs. control $(0 \mathrm{~mol} / \mathrm{l})$ group.
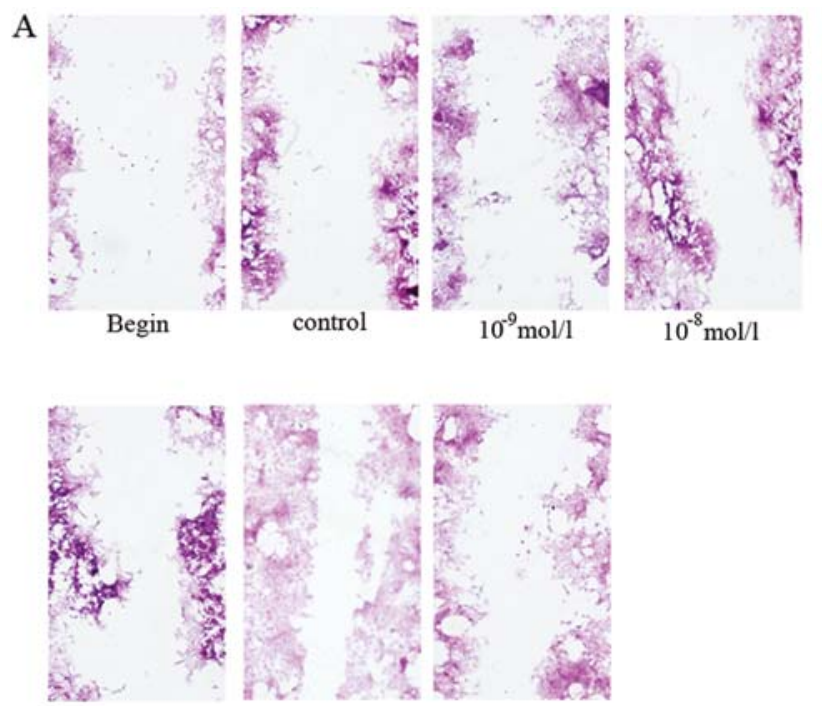

$10^{-7} \mathrm{~mol} / 1 \quad 10^{-6} \mathrm{~mol} / 1 \quad 10^{-5} \mathrm{~mol} / 1$

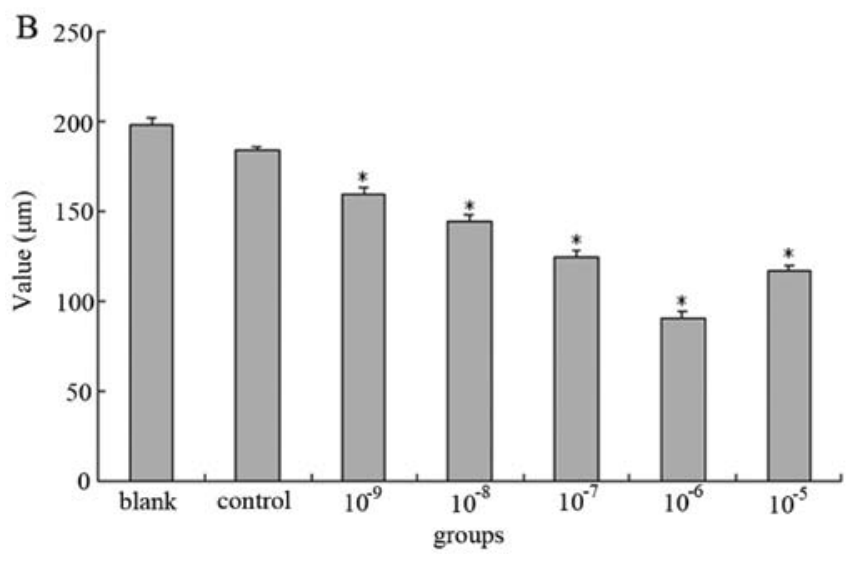

Figure 2. E2 enhances MCF-7 cell migration in a dose-dependent manner (A) Cell migration was measured by monolayer-wounding protocol. (B) Migration was quantified by distance of monolayer-wounding (mean $\pm \mathrm{SD}$, $\mathrm{n}=6)$. ${ }^{*} \mathrm{P}<0.01$ vs. control group.

cell growth and proliferation in multiple tumor cell lines via inhibition of the Ras-ERK MAPK signaling pathway (10). As described above, the effect of E2 on MCF-7 cells might be partly dependent on inhibition of $\mathrm{mfn} 2$. To investigate the involvement of $\mathrm{mfn} 2$ in E2-induced cell proliferation and migration, MCF-7 cells were transfected with the expression vector pEGFP-mfn2. As shown in Fig. 3A and B, normal cultured MCF-7 cells (C) had standard expression levels of mfn 2 and PCNA. However, both untransfected MCF-7 cells stimulated with $10^{-6} \mathrm{~mol} / 1 \mathrm{E} 2$ (E2), and control vector transfected cells stimulated with $10^{-6} \mathrm{~mol} / \mathrm{l} \mathrm{E} 2(\mathrm{E} 2+\mathrm{C})$ showed notably decreased $\mathrm{mfn} 2$ expression and enhanced PCNA expression. In comparison with MCF-7 cells transfected with control vector, mfn2 levels were increased by 2.11-fold and PCNA levels were decreased by about $42.61 \%$ in MCF-7 cells transfected with specific $\mathrm{mfn} 2$ expression vector $(\mathrm{E} 2+\mathrm{mfn} 2)$ $(\mathrm{P}<0.01)$. Consistent with the western blot analysis results, immunofluorescence also revealed that the $\mathrm{mfn} 2$ vector reversed E2-induced downregulation of PCNA protein (Fig. 3C and D).

Cells transfected with the $\mathrm{mfn} 2$ vector showed moderate resistance to E2 stimulation. In comparison with E2-stimulated untransfected or control vector-transfected cells, mfn 2 expression vector-transfected cells demonstrated decreased cell migration (Fig. 4). The wound-healing assay indicated that MCF-7 cells and control vector-transfected cells stimulated by E2 almost completely healed the wound, as compared with unstimulated cells. However, this alteration was reversed by transfection with the $\mathrm{mfn} 2$ expression vector.

ER $\beta$ ameliorates E2-induced $m f n 2$ downregulation in MCF-7 cells. As stated previously, estrogen's effects are mediated through two ERs, ER $\alpha$ and ER $\beta$ (3-6). We hypothesized that $\mathrm{ER} \beta$ might also act upstream of $\mathrm{mfn} 2$, because $\mathrm{mfn} 2$ is identically regulated by E2. To test our hypothesis, MCF-7 cells were transfected with an ER $\beta$ expression vector. As seen in Fig. 5, MCF-7 cells transfected with the ER $\beta$ vector showed high ER $\beta$ protein expression after stimulation with E2 for $24 \mathrm{~h}$. However, no changes in ER $\beta$ protein levels were found in MCF-7 cells transfected with blank control vector or in untransfected MCF-7 cells. In comparison with MCF-7 cells transfected with blank vector, ER $\beta$ protein was increased by about 2.25 -fold in MCF-7 cells transfected with the ER $\beta$ vector $(\mathrm{P}<0.01)$. Cells transfected with the ER $\beta$ vector showed antagonistic effects on E2 stimulation; $\mathrm{mfn} 2$ protein was upregulated in these cells as compared with blank vector-transfected MCF-7 cells and untransfected cells treated with E2. These results indicated that MCF-7 cells transfected with the ER $\beta$ vector showed moderate resistance to E2 stimulation and subsequent decreased downregulation of $\mathrm{mfn} 2$ protein (Fig. 5).

An ER $\beta$ expression vector effectively suppressed E2-induced enhancement of proliferation and migration in MCF-7 cells. The results above showed that $\mathrm{mfn} 2$ negatively regulated E2-induced proliferation and migration of MCF-7 cells and $\mathrm{ER} \beta$ acted as an upstream signal of $\mathrm{mfn} 2$; therefore, we hypothesized that $E R \beta$ could also inhibit proliferation and migration of MCF-7 cells. To investigate this hypothesis, MCF-7 cells were transfected with the ER $\beta$ expression vector (pEGFP-N1-ESR2). An MTT assay was used to examine the proliferation of MCF-7 cells. As shown in Table III, there were significant differences of absorbance of MTT substrate at $490 \mathrm{~nm}$ between experimental groups and the control group. MCF-7 cells transfected with the ER $\beta$ expression vector showed moderate resistance to 


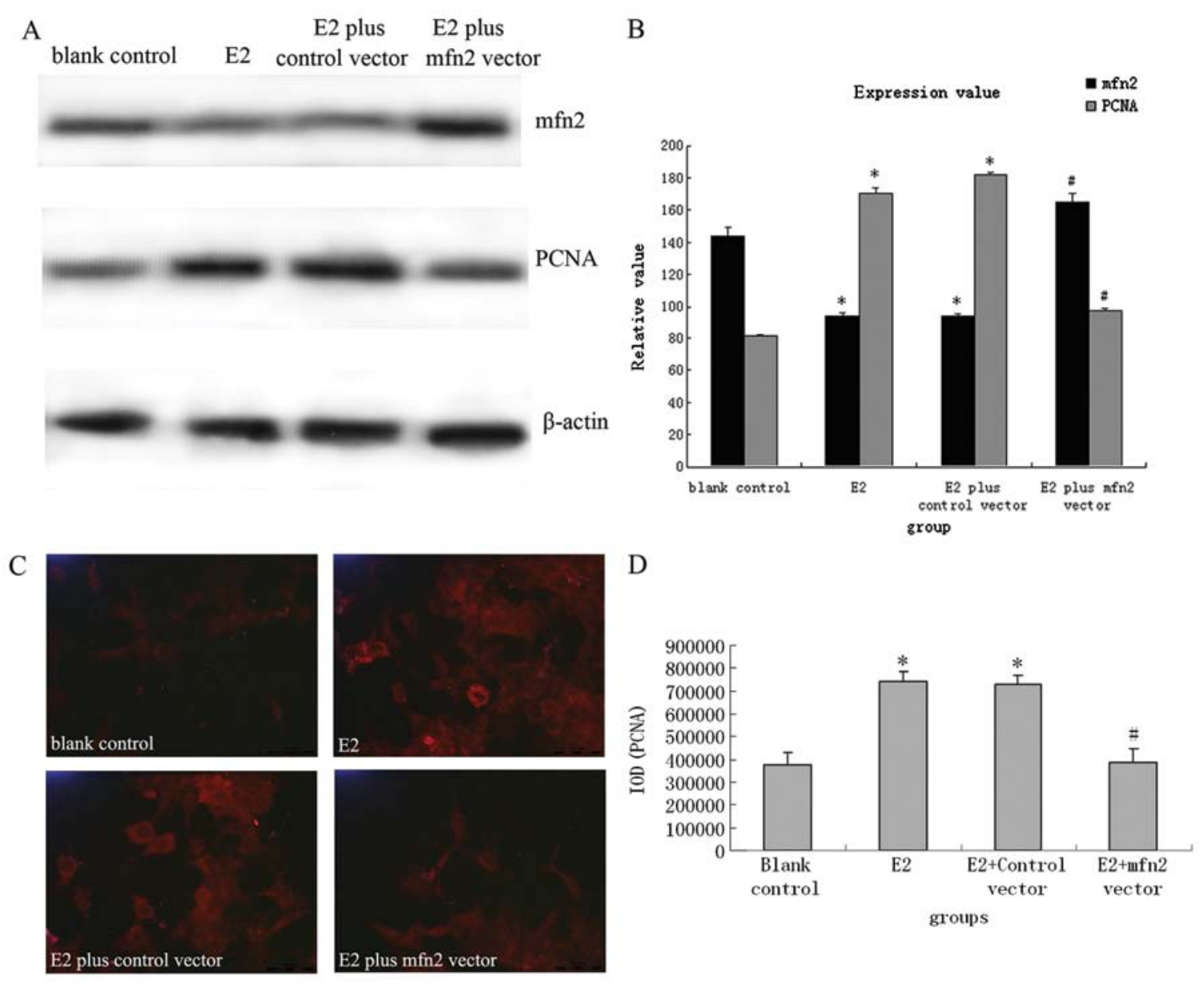

Figure 3. An mfn2 expression vector effectively suppressed E2-induced PCNA expression in MCF-7 cells. (A and B) Expression of mfn2 and PCNA was measured by western blot analysis and quantified by densitometry (mean $\pm \mathrm{SD}, \mathrm{n}=6$ ). ${ }^{*} \mathrm{P}<0.01$ vs. control group; ${ }^{~} \mathrm{P}<0.01$ vs. E2 group. (C and $\left.\mathrm{D}\right)$ Expression of $\mathrm{PCNA}$ was detected by immunofluorescence and quantified by IOD value (mean $\pm \mathrm{SD}, \mathrm{n}=6$ ). ${ }^{*} \mathrm{P}<0.01$ vs. control vector group; ${ }^{*} \mathrm{P}<0.01$ vs. E2 group.
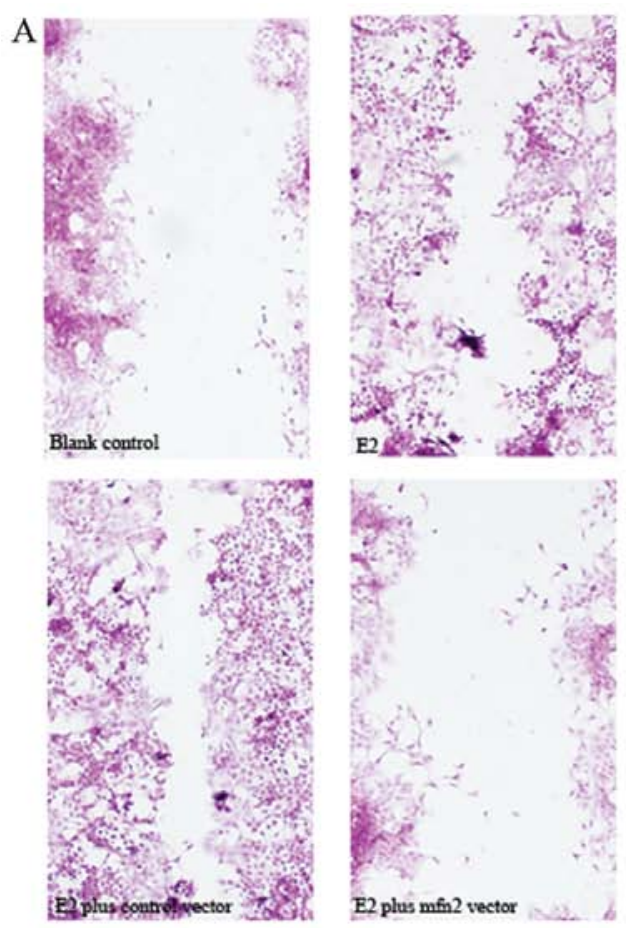

B

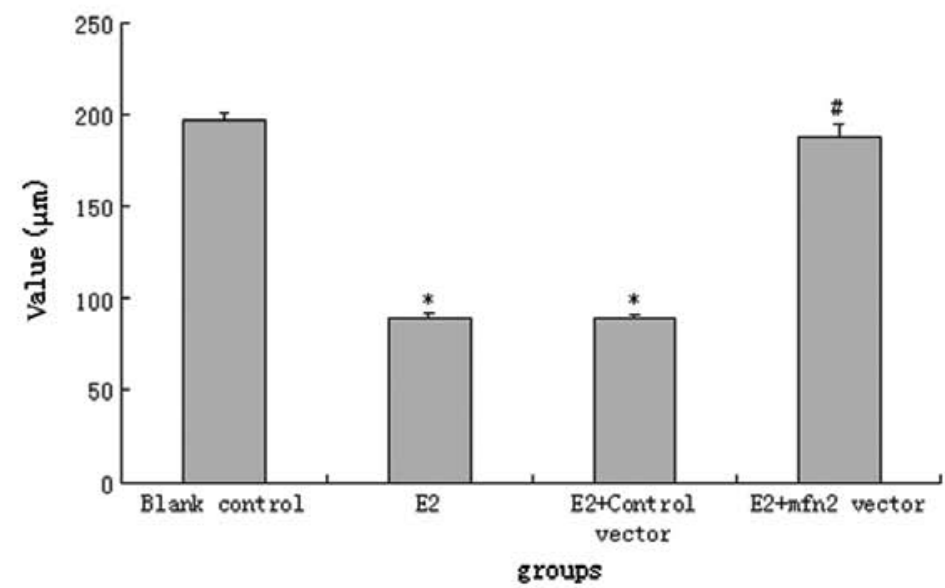

Figure 4. An mfn2 expression vector effectively suppressed E2-induced enhancement of migration in MCF-7 cells. (A and B) Cell migration measured by monolayer-wounding protocol and quantified by distance of monolayer-wounding (mean $\pm \mathrm{SD}, \mathrm{n}=6$ ). ${ }^{*} \mathrm{P}<0.01$ vs. control group; ${ }^{*} \mathrm{P}<0.01$ vs. E2 group. 


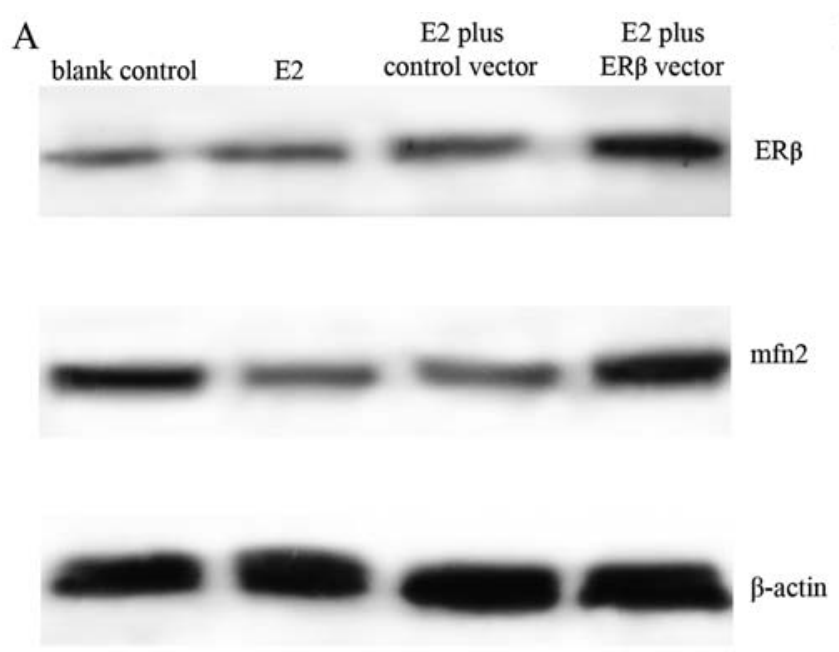

B

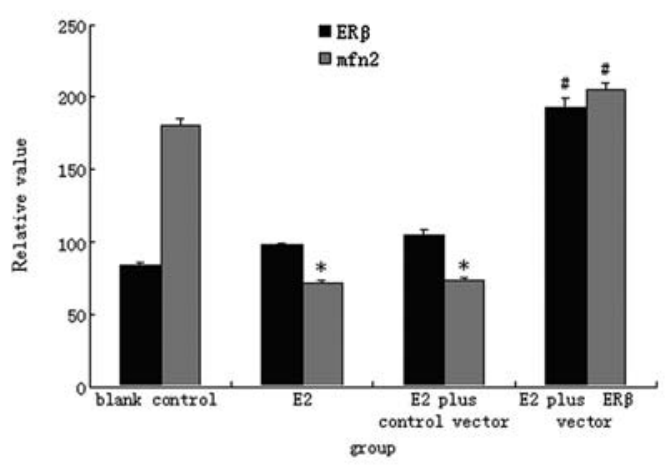

Figure 5. ER $\beta$ ameliorates the E2-induced biologic effects in MCF-7 cells. (A and B) ER $\beta$ vector reversed E2-induced mfn2 downregulation as measured by western blot analysis and quantified by densitometry (mean $\pm \mathrm{SD}, \mathrm{n}=6$ ). ${ }^{*} \mathrm{P}<0.01$ vs. control group; ${ }^{*} \mathrm{P}<0.01$ vs. E2 group.
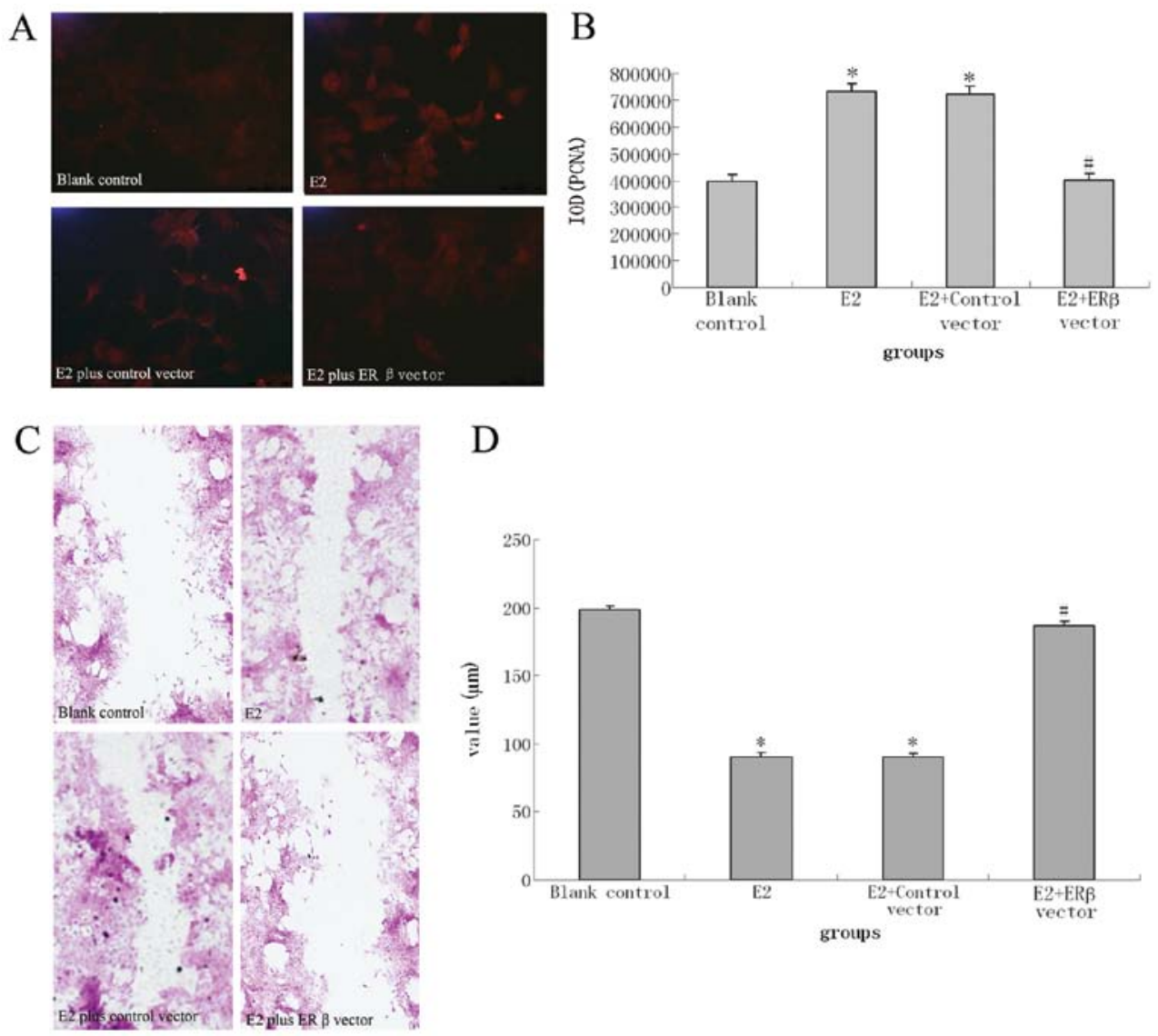

$\mathrm{D}$

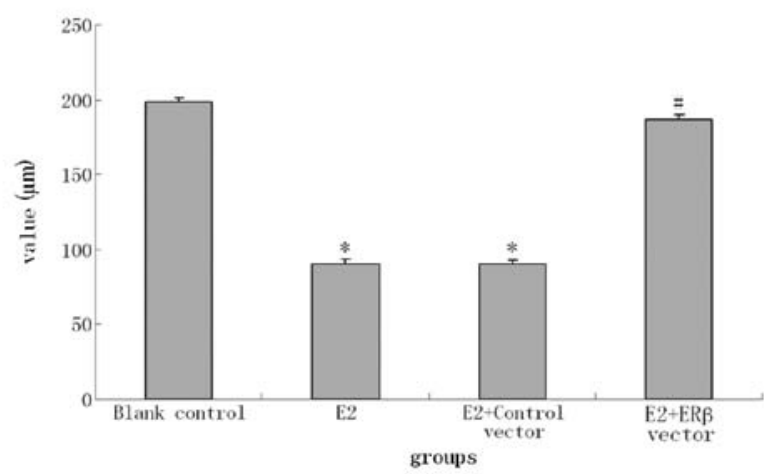

Figure 6. ER $\beta$ ameliorates the E2-induced biologic effects in MCF-7 cells. (A and B) ER $\beta$ vector reversed E2-induced upregulation of PCNA protein as tested by immunofluorescence and quantified by IOD value (mean $\pm \mathrm{SD}, \mathrm{n}=6$ ). ${ }^{*} \mathrm{P}<0.01$ vs. control group; ${ }^{*} \mathrm{P}<0.01$ vs. E2 group. (C and $\mathrm{D}$ ) Cell migration was measured by monolayer-wounding protocol and quantified by distance of monolayer-wounding (mean $\pm \mathrm{SD}, \mathrm{n}=6$ ). ${ }^{*} \mathrm{P}<0.01$ vs. control group; ${ }^{*} \mathrm{P}<0.01$ vs. $\mathrm{E} 2$ group.

E2 stimulation and did not exhibit the enhanced proliferation demonstrated by blank vector-transfected and untransfected MCF-7 cells cultured with medium containing E2. The same results can also be seen in the immunofluorescence detection of PCNA expression (Fig. 6A and B).
To determine if ER $\beta$ influenced cell motility, we examined the ability of transfected cells to migrate in a wound-healing assay. As showed in Fig. 6C and D, there was decreased cell migration of ER $\beta$ expression vector-transfected cells as compared with E2-stimulated untransfected cells and control vector-transfected 
Table III. ER $\beta$ inhibits the E2-induced proliferation of MCF-7 cells as quantified by MTT assay.

\begin{tabular}{lcc}
\hline Group & $\mathrm{n}$ & OD value $(\mathrm{x} \pm \mathrm{s})$ \\
\hline Blank control & 6 & $0.44 \pm 0.03$ \\
E2 & 6 & $0.92 \pm 0.06^{\mathrm{a}}$ \\
E2 plus control vector & 6 & $0.91 \pm 0.02^{\mathrm{a}}$ \\
E2 plus ER $\beta$ vector & 6 & $0.50 \pm 0.04^{\mathrm{b}}$ \\
\hline
\end{tabular}

${ }^{\mathrm{a}} \mathrm{P}<0.01$ vs. control group, ${ }^{\mathrm{b}} \mathrm{P}<0.01$ vs. E2 group.

cells. In fact, the wound-healing assay indicated that MCF-7 cells stimulated by E2 and cells transfected with control vector expressed a stronger ability to heal the wound as compared with normal group cells untreated with E2. However, this ability was reversed by transfection with the ER $\beta$ vector.

\section{Discussion}

It is acknowledged that $\mathrm{ER} \alpha$ and $\mathrm{ER} \beta$ have distinct roles in breast cancer cells. Although the majority considered that ER $\alpha$ promotes proliferation and migration in breast cancer cells and the function of ER $\alpha$ had been clearly elucidated, the exact roles of ER $\beta$ in the pathogenesis of breast cancer are unclear. In fact, the function of ER $\beta$ in the pathogenesis and development of breast cancer is contradictory. Some studies indicate that ER $\beta$ may function as a tumor suppressor and that the loss of ER $\beta$ may promote breast carcinogenesis (16-18); however, there are other studies suggesting that ER $\beta$ may promote cell proliferation and breast tumor formation $(19,20)$. Regardless of these contradictions, the majority of studies focus on the classical model of estrogen signaling through ERs, ER $\alpha$ and ER $\beta$, in which ERs act at ERE-containing promoters. In the classical model, ligand-activated ER binds specifically to DNA at EREs through its DNA binding domain and brings coactivators and corepressors to the transcription site via its activator function (AF)-1 and AF-2 domains. However, an increasing number of studies show that estrogen also modulates gene expression by a second mechanism in which the ER interacts with other transcription factors through a process referred to as transcription factor cross-talk. In this case, the ER modulates the activities of other transcription factors such as activator protein (AP)-1, or SP-1 by stabilizing their binding to DNA and/or recruiting coactivators to the complex $(21,23)$. DeNardo et al (14) reported a model of estrogen-ER activation of AP-1 through interaction with existing coactivator complexes that in turn stabilize the entire complex and/or induce this complex into a higher state of activity. They also identified 6 estrogen-induced/AP-1 dependent genes, including $\mathrm{mfn} 2$, which might fit this model. However, their conclusions were only speculative, as they did not provide detailed data or investigated the interaction of ERs and $\mathrm{mfn} 2$ in vitro. In this study, we investigated the role of ER $\beta$ in estradiol-induced proliferation and migration of human breast cancer cells and studied whether $\mathrm{mfn} 2$ participated in this behavior.

First, we explored whether E2 (17ß-estradiol) affected proliferation and migration of MCF-7 cells, a human breast cancer cell line primarily expressing $\mathrm{ER} \alpha$ and thus mimicking the majority of ER-positive breast tumors. Similar to some previous studies that revealed that E2 affected biological behavior of human breast cells (24-26), our results showed that both the proliferation and migration abilities of MCF-7 were significantly increased when cultured with increasing doses of E2. Furthermore, regulation was in a dose-dependent manner, with the maximum effect seen in the $10^{-6} \mathrm{~mol} / \mathrm{l}$ group. These data suggest that E2 and ER $\alpha$ are positive regulators of MCF-7 cells.

Whether mfn2 was involved in the initiation and progression of human breast cancer has not been previously reported. To investigate the role of $\mathrm{mfn} 2$, we observed the expression of mfn2 in MCF-7 cells cultured within defferent doses of E2. Interestingly, we found that E2 could decrease mfn2 expression in a dose-dependent manner, and that the changes in $\mathrm{mfn} 2$ levels were correlated with the proliferation and migration of MCF-7 cells. These results indicated that $\mathrm{mfn} 2$ might negatively regulate estradiol-induced proliferation and migration of MCF-7 cells. Furthermore, we found that introduction of $\mathrm{mfn} 2$ blocked the response of MCF-7 cells to E2. Thus, mfn2 plays an important regulatory role in E2-induced proliferation and migration of MCF-7 cells. Considering the reports that $\mathrm{mfn} 2$ is one of the estrogen-induced/AP-1 dependent genes (14), the above results suggested that $\mathrm{mfn} 2$ might negatively regulate E2-induced MCF-7 cell proliferation and migration by a non-classical pathway. Mfn2, a proliferation-inhibiting gene, targets to the outer membrane of mitochondria. The $\mathrm{mfn} 2$ gene was found to play roles in the inhibition of cellular proliferation and the promotion of apoptosis (10) and exhibits antitumor activity in a wide range of cancer cell lines (27-29), suggesting that mfn2 may be important in the development of human cancers. Again, the present study also provided a potential target for prevention or treatment for breast cancer patients with ER $\alpha$ positive expression.

Approximately $70 \%$ of breast tumors express ER $\beta$, and most tumors coexpress both ER $\alpha$ and ER $\beta(30,31)$. However, whether ER $\beta$ is involved in E2-induced downregulation of $\mathrm{mfn} 2$ is still unknown. Clearly, additional studies are needed to clarify the role of ER $\beta$ in breast cancer. In the present study, we introduced ER $\beta$ into MCF-7 cells and investigated the effects of ER $\beta$ on proliferation and migration of MCF-7 cells as well as its effects on $\mathrm{mfn} 2$ expression. Our studies demonstrate that ER $\beta$ changes the phenotype of MCF-7 cells in response to E2. In ER $\alpha$-expressing MCF-7 cells, E2 causes proliferation and migration, as well as suppression of $\mathrm{mfn} 2$. In contrast, when ER $\beta$ is expressed along with ER $\alpha$, MCF-7 cells are directed to antitumor pathways and high levels of $\mathrm{mfn} 2$ even in the presence of estrogens. These results suggest that $\operatorname{ER} \beta$ can alter the response of MCF-7 to estrogens and demonstrate that ER $\beta$ may function as a tumor suppressor through the $\mathrm{mfn} 2$ pathway. Many cell-based studies suggest that ER $\beta$ acts as a negative modulator of ER $\alpha$ action. When ER $\alpha$ and ER $\beta$ are co-transfected into ER negative (ER-) cells, ER $\beta$ inhibits ER $\alpha$ transcriptional activity and decreases the sensitivity of the cells to E2 (6,32). ER $\beta$ also lowers both ER $\alpha$ mRNA and protein levels in MCF-7 cells, thus indirectly influencing function of ER $\alpha(33,34)$. ER $\beta$ overexpression in MCF-7 breast cancer cells can not only inhibit ER $\alpha$ regulation of a subset of genes involved in DNA replication, cell-cycle regulation, and proliferation $(35,36)$, but also inhibit cell proliferation in response to E2 (34,36-38), in part by increasing expression of antiproliferative genes (p21 $1^{\text {Cip1 }}$ 
and $\mathrm{p} 27^{\mathrm{Kipl}}$ ). Our results were quite similar to these reports, and minor deference lie in downstream factors. There may be diverse mechanisms for the effect of ER $\beta$ on the response of ER $\alpha$ to E2. Recently, some studies revealed in series that the responses of breast cancer cell lines to $17 \beta$-estradiol are dependent on the ER $\alpha / E R \beta$ ratio $(39,40)$. Most importantly, ER $\beta$ might regulate $\mathrm{mfn} 2$ expression directly in a non-classical pathway similar to ER $\alpha$. Therefore, further studies are needed to determine the exact mechanisms of interaction between ERs, ER $\alpha$ and $E R \beta$, and $\mathrm{mfn} 2$, especially to delineate the mechanism of action through experiments such as in-depth promoter analysis and CHIP.

\section{References}

1. MacGregor JI and Jordan VC: Basic guide to the mechanisms of antiestrogen action. Pharmacol Rev 50: 151-196, 1998.

2. Sommer S and Fuqua SA: Estrogen receptor and breast cancer. Semin Cancer Biol 11: 339-352, 2001.

3. Green S, Walter P, Greene G, et al: Cloning of the human oestrogen receptor cDNA. J Steroid Biochem 24: 77-83, 1986.

4. Kuiper GG, Enmark E, Pelto-Huikko M, et al: Cloning of a novel receptor expressed in rat prostate and ovary. Proc Natl Acad Sci USA 93: 5925-5930, 1996.

5. Katzenellenbogen BS, Montano MM, Ediger TR, et al: Estrogen receptors: selective ligands, partners, and distinctive pharmacology. Recent Prog Horm Res 55: 163-193, 2000.

6. Nilsson S, Makela S, Treuter E, et al: Mechanisms of estrogen action. Physiol Rev 81: 1535-1565, 2001.

7. Speirs V, Carder PJ, Lane S, et al: Oestrogen receptor $\beta$ : what it means for patients with breast cancer. Lancet Oncol 5: 174-181, 2004.

8. Dahlman-Wright K, Cavailles V, Fuqua SA, et al: International Union of Pharmacology. LXIV. Estrogen receptors. Pharmacol Rev 58: 773-781, 2006.

9. Harris HA: Estrogen receptor- $\beta$ : recent lessons from in vivo studies. Mol Endocrinol 21: 1-13, 2007.

10. Chen KH, Guo X, Ma D, et al: Dysregulation of HSG triggers vascular proliferative disorders. Nat Cell Biol 6: 872-883, 2004.

11. Neuspiel M,Zunino R, Gangaraju S, et al: Activated mitofusin 2 signals mitochondrial fusion, interferes with Bax activation, and reduces susceptibility to radical induced depolarization. J Biol Chem 280: 25060-25070, 2005.

12. Santel A, Frank S, Gaume B, et al: Mitofusin-1 protein is a generally expressed mediator of mitochondrial fusion in mammalian cells. J Cell Sci 116: 2763-2774, 2003.

13. Sugioka R, Shimizu S and Tsujimoto Y: Fzo1, a protein involved in mitochondrial fusion, inhibits apoptosis. J Biol Chem 279 52726-52734, 2004.

14. DeNardo DG, Kim HT, Hilsenbeck S, et al: Global gene expression analysis of estrogen receptor transcription factor cross talk in breast cancer: identification of estrogen-induced/ activator protein-1-dependent genes. Molecular Endocrinology 19: 362-378, 2005.

15. Ma L, Liu YP, Geng CZ, et al: Low-dose epirubicin inhibits ezrin-mediated metastatic behavior of breast cancer cells. Tumori 97: 400-405, 2011

16. Ström A, Hartman J, Foster JS, et al: Estrogen receptor beta inhibits 17beta-estradiol-stimulated proliferation of the breast cancer cell line T47D. Proc Natl Acad Sci USA 101: 1566-1571, 2004.

17. Secreto FJ, Monroe DG, Dutta S, et al: Estrogen receptor alpha/beta isoforms, but not betacx, modulate unique patterns of gene expression and cell proliferation in Hs578T cells. J Cell Biochem 101: 1125-1147, 2007.

18. Chen L, Qiu J, Yang C, et al: Identification of a novel estrogen receptor betal binding partner, inhibitor of differentiation-1, and role of ERbeta1 in human breast cancer cells. Cancer Lett 278: $210-219,2009$.

19. Jensen EV, Cheng G, Palmieri C, et al: Estrogen receptors and proliferation markers in primary and recurrent breast cancer. Proc Natl Acad Sci USA 4: 4, 2001.
20. Speirs V, Malone C, Walton DS, et al: Increased expression of estrogen receptor $\beta$ mRNA in tamoxifen-resistant breast cancer patients. Cancer Res 59: 5421-5424, 1999.

21. Kushner PJ, Agard DA, Greene GL, et al: Estrogen receptor pathways to AP-1. J Steroid Biochem Mol Biol 74: 311-317, 2000.

22. Wang W, Dong L, Saville B, et al: Transcriptional activation of E2F1 gene expression by $17 \beta$-estradiol in MCF-7 cells is regulated by NF-Y-Sp1/estrogen receptor interactions. Mol Endocrinol 13: 1373-1387, 1999.

23. Safe S: Transcriptional activation of genes by $17 \beta$-estradiol through estrogen receptor-Sp1 interactions. Vitam Horm 62: 231-252, 2001

24. Ru Lee W, Chen CC, Liu S, et al: 17 beta-estradiol (E2) induces cdc25A gene expression in breast cancer cells by genomic and non-genomic pathways. J Cell Biochem 99: 209-220, 2006.

25. Yoshioka H, Hiromori Y, Aoki A, et al: Possible aryl hydrocarbon receptor-independent pathway of 2,3, 7, 8-tetrachlorodibenzo-p-dioxin-induced antiproliferative response in human breast cancer cells. Toxicol Lett 211: 257-265, 2012.

26. Singh KP, Treas J, Tyagi T, et al: DNA demethylation by 5-aza2-deoxycytidine treatment abrogates 17 beta-estradiol-induced cell growth and restores expression of DNA repair genes in human breast cancer cells. Cancer Lett 316: 62-69, 2012.

27. Wang W, Zhou D, Wei J, et al: Hepatitis B virus X protein inhibits p53-mediated upregulation of mitofusin-2 in hepatocellular carcinoma cells. Biochem Biophys Res Commun 421: 355-360, 2012

28. Jin B, Fu G, Pan H, et al: Anti-tumour efficacy of mitofusin-2 in urinary bladder carcinoma. Med Oncol 28 (Suppl 1): S373-S380, 2011.

29. Rehman J, Zhang HJ, Toth PT, et al: Inhibition of mitochondrial fission prevents cell cycle progression in lung cancer. FASEB J 26: 2175-2186, 2012

30. Dotzlaw H, Leygue E, Watson PH, et al: Expression of estrogen receptor- $\beta$ in human breast tumors. J Clin Endocrinol Metab 82: 2371-2374, 1997.

31. Fuqua SA, Schiff R, Parra I, et al: Estrogen receptor $\beta$ protein in human breast cancer: correlation with clinical tumor parameters. Cancer Res 63: 2434-2439, 2003.

32. Pettersson K, Delaunay F and Gustafsson JA: Estrogen receptor $\beta$ acts as a dominant regulator of estrogen signaling. Oncogene 19: 4970-4978, 2000.

33. Matthews J, Wihlen B, Tujague M, et al: Estrogen receptor (ER) $\beta$ modulates ER $\alpha$-mediated transcriptional activation by altering the recruitment of c-Fos and c-Jun to estrogen-responsive promoters. Mol Endocrinol 20: 534-543, 2006.

34. Chang EC, Frasor J, Komm B, et al: Impact of estrogen receptor $\beta$ on gene networks regulated by estrogen receptor $\alpha$ in breast cancer cells. Endocrinology 147: 4831-4842, 2006.

35. Lin CY, Strom A, Li Kong S, et al: Inhibitory effects of estrogen receptor beta on specific hormone-responsive gene expression and association with disease outcome in primary breast cancer. Breast Cancer Res 9: R25, 2007.

36. Williams C, Edvardsson K, Lewandowski SA, et al: A genomewide study of repressive effects of estrogen receptor beta on estrogen receptor alpha signaling in breast cancer cells. Oncogene 27: 1019-1032, 2008.

37. Paruthiyil S, Parmar H, Kerekatte V, et al: Estrogen receptor $\beta$ inhibits human breast cancer cell proliferation and tumor formation by causing a G2 cell cycle arrest. Cancer Res 64: 423-428, 2004.

38. Behrens D, Gill JH and Fichtner I: Loss of tumourigenicity of stably ER $\beta$-transfected MCF-7 breast cancer cells. Mol Cell Endocrinol 274: 19-29, 2007.

39. Nadal-Serrano M, Sastre-Serra J, Pons DG, et al: The ERalpha/ ERbeta ratio determines oxidative stress in breast cancer cell lines in response to 17beta-estradiol. J Cell Biochem 113: 3178-3185, 2012

40. Sastre-Serra J, Nadal-Serrano M, Pons DG, et al: The effects of $17 \beta$-estradiol on mitochondrial biogenesis and function in breast cancer cell lines are dependent on the ER $\alpha / E R \beta$ ratio. Cell Physiol Biochem 29: 261-268, 2012. 